Rabaska

Revue d'ethnologie de l'Amérique française

\title{
Muséologie et gouvernance selon Roland Arpin
}

Volume 15, 2017

URI : https://id.erudit.org/iderudit/1041125ar

DOI : https://doi.org/10.7202/1041125ar

Aller au sommaire du numéro

Éditeur(s)

Société québécoise d'ethnologie

ISSN

1703-7433 (imprimé)

1916-7350 (numérique)

Découvrir la revue

Citer ce document

(2017). Muséologie et gouvernance selon Roland Arpin. Rabaska, 15, 181-182.

https://doi.org/10.7202/1041125ar

Ce document est protégé par la loi sur le droit d'auteur. L'utilisation des services d'Érudit (y compris la reproduction) est assujettie à sa politique d'utilisation que vous pouvez consulter en ligne.

https://apropos.erudit.org/fr/usagers/politique-dutilisation/ 


\section{Place publique}

\section{Points de vue/livres}

\section{Muséologie et gouvernance selon Roland Arpin}

Roland Arpin (1934-2010), pédagogue, communicateur et haut fonctionnaire, a fondé le Musée de la civilisation du Québec en 1987 et l'a dirigé jusqu'en 2001. Au fil des ans, il a eu l'occasion de développer sa pensée sur la muséologie et la gouvernance dans plusieurs écrits. Yves Bergeron et Julie-Anne Côté les ont rassemblés dans deux tomes parus aux éditions de L'Harmattan. Pour en rendre compte, Rabaska a fait appel à trois spécialistes capables d'apprécier son œuvre et d'en mesurer l'impact puisqu'ils ont aussi l'expérience de la direction de musées. Danièle Brochu, responsable des publics au Musée du Louvre (2006-2009), directrice du Manoir de Kernault (EPCC Chemins du patrimoine en Finistère), à Mellac (Bretagne) depuis 2009, et professeure associée à l'Université de Bretagne sud ; Michel Côté, ancien directeur des collections du Musée (1987-1999), directeur général du Musée des confluences à Lyon en France (1999-2010) avant de revenir à la direction générale du Musée de la civilisation (2010-2015) ; et Jean Guibal, conservateur du Musée d'Aoste, Isère, et conservateur directeur du Musée dauphinois de Grenoble (1986-2000).

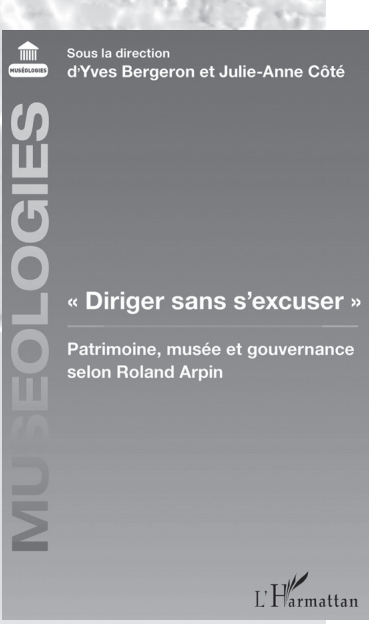

«Diriger sans s'excuser ». Patrimoine, musée et gouvernance selon Roland Arpin. Sous la direction d'Yves Bergeron et de Julie-Anne Côté. L'Harmattan, 2016, 333 p. ISBN 978-2343-09523-3. 
Sous la direction de

Un nouveau musée pour un nouveau monde Musée et muséologie selon Roland Arpin

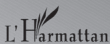

Un nouveau musée pour un monde nouveau. Musée et muséologie selon Roland Arpin. Sous la direction d'Yves Bergeron et de Julie-Anne Côté. L'Harmattan, 2016, 342 p. ISBN 978-2343-09524-0.

\section{Faire confiance à l'intelligence de chacun}

DANIÈLE BROCHU

Responsable du Service des publics de l'EpcC Chemins du patrimoine et directrice du Manoir de Kernault

Entre 1983 et 2003, Roland Arpin rédige de nombreux discours, conférences et articles. Il conserve l'ensemble de ces textes qu'il classe chronologiquement et thématiquement dans des classeurs sous le vocable général « Conférences », qu'ils aient été publiés ou non. En 2003, il les confie à Yves Bergeron qui les fait numériser quelques années plus tard par l'Université du Québec à Montréal (UQÀM) puis ils sont finalement déposés aux archives du Musée de la civilisation.

Les deux ouvrages, Un nouveau musée pour un nouveau monde. Musée et muséologie selon Roland Arpin et « Diriger sans s'excuser 》. Patrimoine, musée et gouvernance selon Roland Arpin, publiés dans la collection « Muséologies », dirigée par François Mairesse et Michel Van Praët, proposent une sélection de ces textes, rédigés entre 1987 et 2003. Ils sont complétés, éclairés, parfois mis en valeur par des contributions extérieures.

Chacun à leur manière, mais avec de nombreux points communs, ces recueils proposent une sorte de «(re)découverte active » de la pensée, du 